\title{
Sosyo-Kültürel Farklılıkların Mekân Kullanımına Etkilerine Karşılaştırılmalı Bir Örnek: Kültür ve Gülveren Mahalleleri
}

\section{A Comparative Sample of the Effects of Socio-Cultural Differences in the Use of Place: The "Kültür" and "Gülveren" Neighbourhoods}

\section{Mustafa ERTÜRK* Gökhan GÖKDEMIR**}

\begin{abstract}
Öz: Kültür, toplumların tarih boyunca ürettikleri maddi ve manevi değerlerin bütününü ifade eder. İnsanların mekânları oluşturma ve kullanma şekilleri de kültürün birer yansıması olan ögelerdir. Değişik sosyo-kültürel yapı ve anlayışa sahip toplulukların, mekânsal ihtiyaçlarında ve mekânı kullanım şekillerinde farklılıklar olduğu düşünülmektedir. Bu amaçla, sosyo-kültürel farkların, yan yana bulunan iki mahallede, mekânlara olan etkilerinin ne düzeyde olduğunu araştırmak ve bu konuda literatürde var olan eksiliğin giderilmesine katkı sağlamak istenmektedir. Bu çalışmada Antalya'nın mahalle bazındaki sosyokültürel farklarının mekân kullanımına etkisi incelenmiştir. Araştırma sahası olarak kültürel farkların olduğu düşünülen Kepez ilçesine bağll, Kültür ile Gülveren mahalleleri seçilmiştir. Konu ve araştırma sahası hakkında içerik analizi yapılmış, gözlem ve görüşmeler sonucunda ortaya çıkan bilgilerle birlikte, söz konusu mahalleler karşılaştırılmıştır. Elde edilen bulgulara göre, daha iyi bir ekonomik yapının bulunduğu ve üniversite öğrencilerinin yoğunluğuyla birlikte kültürel bir çeşitliliğe de sahip olan Kültür Mahallesi'nde mekânların türleri, sayıları ve kullanım şekillerinin, Gülveren Mahallesi'ne göre oldukça gelişmiş bir durumda olduğu görülmektedir. Sonuç olarak, sosyo-kültürel farkların (ekonomik gelir, eğitim durumu, kültürel alışkanlıklar vb.) Kültür ve Gülveren mahallelerinde, mekân kullanımında önemli değişiklikler ortaya çıkarttığı tespit edilmiş̧ir.
\end{abstract}

Anahtar sözcükler: Kültür, Kültür Coğrafyası, Sosyo-Kültürel Farklılıklar, Mekân, Mekân Kullanımı

Abstract: Culture expresses the whole material and moral values that societies have produced in their history. The types of people's constituting and using places are also one of the items that reflection the culture. It is thought that the need for place and the variations in using places have differences among those communities having different socio-cultural structures and attitudes. For the purpose of this research, 2 neighborhoods that are (in a side by side position),were researched for the effects of sociocultural differences in the use of sites, also in this respect, to overcome the lack of this research in the literature. In this study; the effect of socio-cultural differences in the usage of place in Antalya in terms of neighbourhoods, has been studied. Being loyal to the district of "Kepez", "Kültür" and "Gülveren" neighbourhoods, where it was thought there are cultural differences, was the chosen field of research. Content analysis was made about the topic and the area of research, the neighbourhoods were compared, together with the information supplied through observations and from meetings. According to the finds obtained; it is seemed that; in the "neighbourhood of Kültür", where there has been a better economic structure and cultural variety, together with density of university students, the types, numbers and usages of places are in a quite advanced structure, in comparison with the "neighbourhood of Gülveren". As a result; it has been determined that the socio-cultural differences in the Kültür and Gülveren neighbourhoods of Antalya, result in important differences in the use of place.

Keywords: Culture, Cultural Geography, Socio-Cultural Differences, Place, Using Place

\footnotetext{
* Doç. Dr., Akdeniz Üniversitesi, Edebiyat Fakültesi, Coğrafya Bölümü, Antalya. merturk19@hotmail.com

** Arş. Gör. Akdeniz Üniversitesi, Edebiyat Fakültesi, Coğrafya Bölümü, Antalya.gokhan_gok@outlook.com
} 


\section{Giriş}

İlk çağlardan günümüze sürekli bir gelişim içerisinde olan insanoğlu, bu süreçte kendine özgü birtakım özellikler meydana getirmiştir. Coğrafyalar ve toplumlar arasında çeşitlilik gösteren bu özellikler milletlerin kültürlerini ortaya çıkarmıştır. Aynı geçmiş, gelenek, duygu ve alışkanlıklara sahip insanların oluşturduğu bir yaşam biçimi olarak kabul edilen kültür, maddi ögeler, davranışlar, değer ve tutumlardan oluşmaktadır (Özey 2014). Bu etmenler toplumların günlük hayatına, insan ilişkilerine, değer yargılarına, beslenme şekillerine, giyim kuşamlarına ve mimari anlayışına kadar çok çeşitli şekillerde etki eder. Kültür, çevrenin insan tarafından oluşturulan bölümü olarak da tanımlanmaktadır (Tümertekin \& Özgüç 2010). Bir diğer tanıma göre, inanç kümeleri ya da değerlerin yaşam biçimlerini şekillendirmesi ve bunların aracılığıyla maddi ve sembolik ögeleri oluşturmasıdır (Crang 1998). Diğer bir ifade de ise içerisine bilgi, sanat, ahlak, hukuk, adetler ve insanların toplumun bir ferdi olması sayesinde kazanmış olduğu kabiliyet ve alışkanları da alan bir olgudur (Erkal 1982).

Kültürel özellikler topluluklar arasında farkl1lıklar gösterir (Hoffman 2006). Toplumların yıllar boyu süren serüvenlerinde kültürler, onlarla birlikte değişime, gelişime uğrar ve yeni kuşaklara aktarılır. Kültürün özü aynı kalmak kaydıyla, başka kültürlerle ilişki kurma ve teknolojinin gelişmesi gibi nedenlerle içeriği değişebilmektedir. Eğer değişmezse toplumun ihtiyaçlarına cevap veremez bir hale gelir (Arslanoğlu 2000). Kültürel değişim sürecinde, evrimleşen değerler sistemi "popüler kültür" formunu ortaya çıkarmıştır. Kültür kavramının değişken bir kavram olması nedeniyle toplumların ilgilerinin, beğenilerinin ve eğilimlerinin yansıması sonucunda kitlesel bir eğilim veya dönüşüm süreci yaşanmaktadır. Bu kitlesel beğeni farklılıkları popüler kültür kavramını işaret eder (Limon 2012). Popüler kültür bir çabuk kullanım ve tüketim kültürü olarak ifade edilmektedir (Erdoğan 2004). Günümüzün yüksek iletişim teknolojileri, gelişmiş ulaşım imkânları ve küreselleşme sayesinde kültürel ögeler dünyanın neredeyse her yerine kolayca yayılabilmektedir. Böylece dünyanın pek çok yerinde aynı anda benzer kültürel eğilimler ve ögeler ortaya çıkabilmektedir. Bu eğilimler sonucu insanların davranış tarzından yeme içme alışkanlıklarına, giyim kuşamlarından örf ve adetlerine, sosyal aktivitelerinden dinledikleri müziklere ve mekânı kullanma şekillerine kadar pek çok değişim yaşanabilmektedir. Bu değişimlerin bazı somut örnekleri, genç nesil ve özellikle de üniversite öğrencileri arasında yaygın olarak görülmektedir. Genellikle üniversite öğrencileri, iletişim araçlarını yoğun bir şekilde kullanmakta bu sayede sürekli birbirleriyle ve dünyanın diğer kesimleri ile bağlantı halinde kalmaktadır. Burada kitle iletişim araçları, toplumlarda kültürel dönüşümün gerçekleşmesinde ve popüler kültürün yayılmasında önemli rol oynamaktadır (Şahin 2005). Bu sayede üniversite öğrencileri arasında hızla yayılan, kabul gören bir takım ortak görüş ve anlayışlar ortaya çıkabilmektedir. Bu değişimlerin sonuçları öğrencilerin mekân algısında ve mekânları kullanım şekillerinde de kendini gösterir. Mekânsal farklılaşmayı ortaya çıkaran en önemli sebep, teknolojik gelişmelerin sağladığ 1 ulaşılabilirliktir (Hacısalihoğlu 2000). Artık dünyanın değişik pek çok yerinde benzer mekân algıları ve mekân çeşitleri ortaya çıkmakta ve yayılmaktadır. Öğrenciler ise genellikle, dünyada kabul gören ve hızla yayılan fastfood zincirleri, restoranlar, kafeler, eğlence mekânları gibi hızlı yemek yiyebilecekleri, sohbet edip vakit geçirebilecekleri ve eğlenebilecekleri mekânları aramakta ve tercih etmektedir. Bu sebeple özellikle üniversite öğrencilerinin yoğun olarak yaşadığ 1 alanlar bu tarz mekânların gelişimine oldukça uygundur. Genç bir nüfus, bulunduğu yerin tüm tüketim alışkanlarını değiştirmekte ve pek çok yeni faaliyetin gelişmesine katkı sağlamaktadır (Işık 2008). Sonuçta üniversite öğrencileri bulundukları çevrede büyük bir sosyal ve mekânsal dönüşüm meydana getirebilmektedir. 
Araştırma sahası Antalya ilinin Kepez ilçesinde bulunan Kültür ve Gülveren mahalleleridir (Fig. 1). İnceleme yaptığımız mahalleler yan yana bulunmalarına rağmen iki farklı sosyo-kültürel yap1 ve anlayışa sahiptir. $\mathrm{Bu}$ özellikler mahalleler arasında belirgin farklar ortaya çıkarmaktadır. Üniversite öğrencilerinin yoğun olarak yaşadığı Kültür Mahallesi gelişmiş bir sosyal aktivite ve mekân çeşitliliğine sahip iken, genellikle ailelerin barındığ Gülveren Mahallesi'nde tam tersi bir durum yaşanmaktadır. Ortaya çıkan bu farklılıkların temel sebebinin iki mahalledeki sosyo-kültürel farkl11ıklar olduğu düşünülmektedir.

\section{Yöntem}

Bu araştırma, sosyo-kültürel farklılıkların olduğu düşünülen Gülveren ve Kültür mahallelerini kapsamaktadır (Fig. 1). Çalışmada temel amaç, sosyo-kültürel farklılıkların, mekâna olan etkilerinin ne düzeyde olduğunu araştırmak ve sonuçlarını ortaya koyabilmek-



Fig. 1. Araştırma Sahasının Lokasyon Haritası tir. Bu doğrultuda ilk olarak konuyla ilgili çalışmalar incelenerek literatür taraması yapılmış ve var olan kaynaklardan faydalanılmıştır. Daha sonra coğrafya çalışmalarında veri sağlamanın önemli yolları arasında yer alan saha gözlemleri ve görüşmeler gerçekleştirilmiştir. Sahada yapılan gözlemler sonucunda mahallelerde bulunan mekânların tespit ve sınıflandırması yapılmış ve bunlar fotoğraf çekimleriyle desteklenmiştir. Bir sonraki adımda araştırma sahasında bulunan her iki mahallede nüfuslarına uygun olarak belirlenen örneklem gruplarla görüşmeler yapılmıştır. Bu görüşmelerde araştırma konusuna bağlı olarak mahallelerin çeşitli sosyo-kültürel özelliklerine dair verilere ulaşılmaya çalışılmıştır. Mahallelerin sahip olduğu yaş yapısı, eğitim durumu, meslek grupları ve mahalleler içerisinde bulunan mekânların kullanım tercihlerine dair bilgiler toplanmıştır. Sahadan alınan veriler neticesinde, sosyo-kültürel farklılıkların mekân kullanımına etkileri karşılaştırılmıştır.

\section{Amaç ve Varsayım}

$\mathrm{Bu}$ araştırmanın amacı sosyo-kültürel farklılıkların, yan yana bulunan iki mahallede bile, mekânlara olan etkilerinin ne düzeyde olduğunu araştırmak ve ortaya koymaktır. Bu nedenle mekânsal anlamda aralarında belirgin farklılıklar görülen Kültür ve Gülveren mahalleleri seçilmiştir. Sosyo-kültürel özelliklerin, yaşanılan çevreyi önemli şekilde etkilediği ve mekânların gelişimi ve çeşitlenmesinde rol oynadığı düşünülmektedir.

\section{Bulgular}

Her iki mahallede yapılan gözlem ve görüşmeler sonucunda sosyo-kültürel yapılarına ve mekân kullanım ve çeşitliliğine dair verilere ulaşılmıştır. Bu verilere göre mahalleler arasında belirgin farklar ortaya çıkmıştır (Tablo 1 ve 2). 
Tablo 1. Kültür ve Gülveren Mahallelerinin Cinsiyet ve Yaş Grupları Dağılımı

\begin{tabular}{|l|c|c|c|c|c|c|}
\hline & \multicolumn{2}{|c|}{ Cinsiyet } & \multicolumn{4}{c|}{ Yaş Aralı̆̆ı } \\
\cline { 2 - 7 } & Erkek & Kadın & $18-29$ & $30-44$ & $45-59$ & $60+$ \\
\hline Gülveren Mah. & $\% 60$ & $\% 40$ & $\% 13,7$ & $\% 39,3$ & $\% 29,5$ & $\% 17,5$ \\
\hline Kültürr Mah. & $\% 53$ & $\% 47$ & $\% 58,3$ & $\% 19,7$ & $\% 15,8$ & $\% 6,2$ \\
\hline
\end{tabular}

Tablo 2. Kültür ve Gülveren Mahallelerinin Öğrenim Durumu ve Meslek Grupları Dağılımı

\begin{tabular}{|l|c|c|c|c|c|c|c|c|}
\hline & \multicolumn{3}{|c|}{ Öğrenim Durumu } & \multicolumn{5}{c|}{ Meslek } \\
\cline { 2 - 8 } & İlköğretim & Lise & Üniversite & İşci & Memur & $\begin{array}{c}\text { Serbest } \\
\text { Meslek }\end{array}$ & Emekli & $\begin{array}{c}\text { Çalşmıłyor } \\
\text { (Öğrenci dâhil) }\end{array}$ \\
\hline Gülveren Mah. & $\% 29,4$ & $\% 50,6$ & $\% 20$ & $\% 25$ & $\% 10$ & $\% 19,3$ & $\% 15,6$ & $\% 29,4$ \\
\hline Kültür Mah. & $\% 9,3$ & $\% 33,8$ & $\% 56,9$ & $\% 15$ & $\% 7,8$ & $\% 10$ & $\% 5$ & $\% 62,2$ \\
\hline
\end{tabular}

Kültür Mahallesi'ne göre nispeten daha eski bir yerleşim yeri olan Gülveren Mahallesi'nin yaş ortalaması yüksektir. TÜİK verilerine göre 2015 yılı nüfusu 5351 kişiden oluşan mahalle sakinlerini büyük oranda aileler oluşturmaktadır. Mahalle sakinlerinin pek çoğu orta ve düşük gelir seviyesine sahiptir. Hâkim olan meslek grubu \%25 oranında işçilerdir. Eğitim durumlarına göre lise ve ilkokul mezunlarının oranı \%80 civarındadır ve üniversite seviyesinde eğitim görmüş kişilerin sayısı azdır (Tablo 2). Her iki mahalle arasındaki temel farklılardan birisi budur. Hâlihazırda Akdeniz Üniversitesi'nde eğitim gören öğrenciler mahalleyi çok fazla tercih etmemektedir.

Kültür Mahallesi, Gülveren Mahallesi'ne göre daha büyük bir nüfusa ve yüzölçümüne sahiptir. Nispeten yeni kurulmuş bir mahalle olan Kültür, son 5 sene içerisinde hıla gelişmiş ve nüfusu artmıştır. 2015 yılı TÜİK verilerine göre mahallede 11969 kişi yaşamaktadır. Mahallede genç nüfusun oranı \%58,3 civarındadır. Bu nüfusun önemli bir kısmını Akdeniz Üniversitesi öğrencileri oluşturmaktadır. Mahallede ikamet eden pek çok aile de vardır. Mahalle sakinlerinin ortalama aylık geliri yüksektir. Çok sayıda öğrenci barındırmasına rağmen düşük gelirli bir mahalle değildir. Mahallede pek çok meslek grubuna ait çalışan bulunmaktadır. Eğitim düzeyi yüksektir ve üniversite eğitimi görmüş kişilerin oranı \%59,6'dır. Orta yaş ve üzeri kesim genelde lise mezunudur (Tablo 2).

Her iki mahallenin genel durumlarına, mekân çeşitliliğine ve dağılımlarına bakıldığında belirgin farklar ortaya çıktığı görülmektedir.

Gülveren Mahallesi, Kültür Mahallesi’ne göre daha eski bir yerleşim yeridir. Mahallede bulunan binaların pek çoğu orta yaşlıdır ve bazı yerlerde gecekondular yer almaktadır. Mahalledeki evlerin fiyatları ve kira bedelleri düşüktür ve çoğunlukla aileler barınmaktadır. Öğrencilerin kalabileceği apart ve yurt gibi seçenekler oldukça az sayıdadır ve mahallenin öğrenciler tarafından tercih edilmemesinin sebeplerinden birisi budur. Mahallede oldukça az sayıda dükkân bulunmaktadır ve bazı binaların altı dükkân yapmaya müsait değildir.

Tablo 3. Gülveren ve Kültür Mahallelerinde Sosyal Mekân Çeşitliliği

\begin{tabular}{|l|c|c|}
\hline $\begin{array}{l}\text { Sosyal } \\
\text { Mekânlar }\end{array}$ & $\begin{array}{c}\text { Kültür } \\
\text { Mahallesi }\end{array}$ & $\begin{array}{c}\text { Gülveren } \\
\text { Mahallesi }\end{array}$ \\
\hline Market & 23 & 6 \\
\hline Kafe & 12 & 1 \\
\hline Restoran & 24 & 2 \\
\hline $\begin{array}{l}\text { Oyun/Spor } \\
\text { Salonları }\end{array}$ & 6 & 1 \\
\hline Pastane & 9 & 1 \\
\hline Kahvehane & 1 & 1 \\
\hline
\end{tabular}

Mahalle içerisinde bulunan az sayıda dükkân, birkaç market, bakkal, pastane, kafe, kuaför ve hırdavatçıdan oluşmaktadır. Mahallede 1 adet ilkokul ve cami bulunmaktadır. Ayrıca mahalle sınırları içerisinde bir araba galerisi bulunmaktadır. Burası mahalledeki asıl faaliyet 
alanıdır ve Antalya şehrinin pek çok yerinden insanlar buraya gelmektedir. Ancak mahalle geneline bir canlılık kattığını söylemek oldukça güçtür ve kendi çevresine etkileri de son derece sinırlidır.

Kültür Mahallesi'nde ise binaların çoğu yeni yapılardır. Kira ve ev fiyatları Gülveren Mahallesi'ne göre daha yüksektir. Binalardaki dairelerin pek çoğu $1+1$ ve $2+1$ oda şeklinde tasarlanmış ve daha çok üniversite öğrencilerinin tercihlerine uygun şekilde düzenlenmiş eşyalı evlerdir. Mahallede sürekli yeni binalar inşa edilmekte ve bunların tamamına yakını apart şeklinde yapılmaktadır. Ayrıca mahallede bir KYK merkezi, bir KYK yurdu ve çok sayıda özel yurt bulunmaktadir.

Kültür Mahallesi'nde bulunan dükkânlar belirli caddeler üzerinde dizilmiş haldedir.

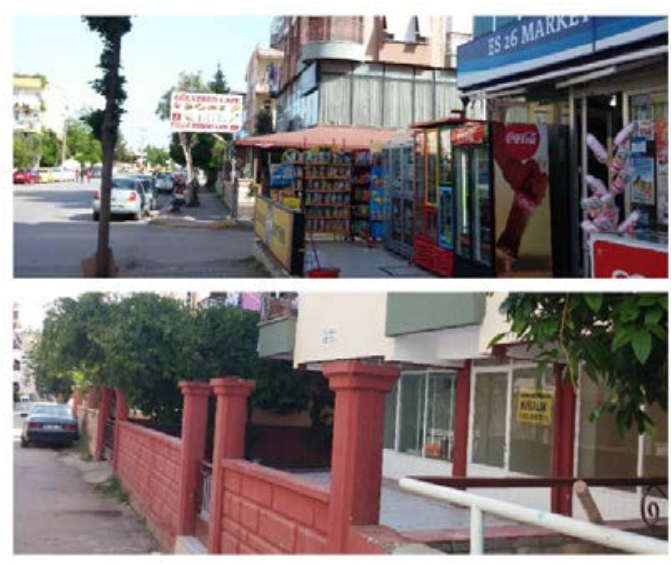

Fig. 2. Gülveren Mahallesi Mekânları Mahallenin ana kalbini oluşturan Hürriyet Caddesi en işlek ve yoğun alandır. Burada mahallenin neredeyse bütün ihtiyaçlarına cevap verebilecek 40 civarında dükkân bulunmaktadır (Tablo 3). Bu cadde üzerindeki mekânlar sabah saatlerinden gece geç saatlere kadar yoğun bir şekilde çalışmaktadır. Mahallenin kuzeyinde Ulusoy ve batısında 75. Yıl Caddeleri de yine benzer bir çeşitliliğe sahiptir ancak Hürriyet Caddesi kadar potansiyelleri bulunmamaktadır. Mahalle içerisinde ve ara sokaklarda dükkân yok denecek kadar azdır, bu durumun sebebi bütün binaların bahçeli yapılması ve altlarının dükkân yapılmaya müsait olmamasıdır. Buna rağmen mahallede 75 tane sosyal mekân bulunmaktadır. Mahallede 1 adet ilkokul, 4 adet cami ve birkaç adet küçük park alanı vardır.
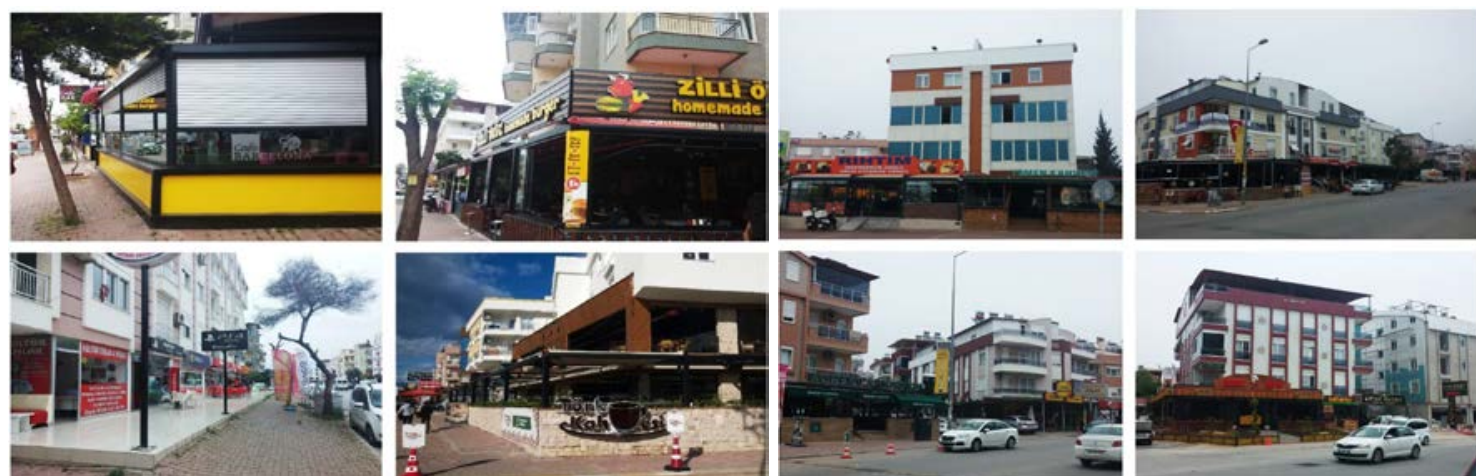

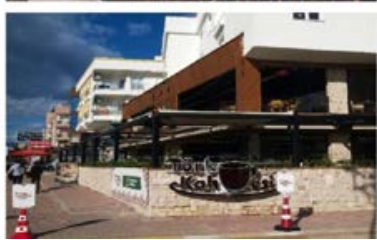

Fig. 3. Kültür Mahallesi Mekânları-1


Fig 4. Kültür Mahallesi Mekânları-2

Gülveren Mahallesi sakinlerinin mekân kullanım tercihleri oldukça kısıtlıdır. Yaptığımız görüşmelerde özellikle orta yaş ve üzeri kesimin kullandıkları mekânların birkaç seçenekten ibaret olduğu görülmüştür. Sosyal yaşamın oldukça zayıf olduğu mahallede genelde kahvehane ve birkaç küçük pastane haricinde kullanılan mekân bulunmamaktadır (Tablo 3). Mahalle sakinlerinin \%52'si bu mekânları ayda 1 veya 2 kez kullandığını \%26'sı ise hiçbir zaman kullanmadığını belirtmiştir. Burada yaşayan az sayıda öğrenci ise mahallede bulunan birkaç adet kafe ve restoranı mecburen tercih ettiklerini ve ortalama haftada $1 \mathrm{kez}$ kullandıklarını belirtmişlerdir (Tablo 5). Bu görüşmelerde alınan en dikkat çekici sonuçlardan birisi bazı Gülveren Mahallesi sakinlerinin s1k sık Kültür Mahallesi'ni tercih etmeleridir. 
Tablo 4. Gülveren ve Kültür Mahallelerinde Sosyal Mekânların Kullanım Oranları

\begin{tabular}{|l|l|l|l|l|l|}
\hline & \multicolumn{5}{l|}{ Sosyal Mekânların Kullanım Oranları } \\
\hline & Kafe & Restoran & Pastane & Kıraathane & Oyun/Spor Salonu \\
\hline Gülveren & $\% 15$ & $\% 24$ & $\% 37$ & $\% 38$ & - \\
\hline Kültür & $\% 67$ & $\% 72$ & $\% 56$ & $\% 11$ & $\% 27$ \\
\hline
\end{tabular}

Tablo 5. Gülveren ve Kültür Mahallelerinde Sosyal Mekânların Kullanım Sıklığı

\begin{tabular}{|l|l|l|l|l|}
\hline & \multicolumn{4}{l|}{ Sosyal Mekânların Kullanım Siklığ1 } \\
\hline & Hergün & Haftada 1 veya 2 kez & Ayda 1 veya 2 kez & Hiçbir zaman \\
\hline Gülveren & $\% 5$ & $\% 17$ & $\% 52$ & $\% 26$ \\
\hline Kültür & $\% 20$ & $\% 45$ & $\% 27$ & $\% 8$ \\
\hline
\end{tabular}

Yapılan mülakatlarda özellikle genç yaştaki kişilerin pek çoğu haftada en az 1 kez Kültür Mahallesi'ndeki kafe ve restoranlara gittiklerini belirtmiş ve bunun sebebi olarak Gülveren Mahallesi'nde bu tarz mekânların yokluğunu sebep göstermişlerdir. Mahalle halkı, günlük ihtiyaçlarını çevredeki bakkal ve birkaç marketten sağlamakta ve sık sık Kültür Mahallesi'ndeki marketlere gitmeyi tercih etmektedirler.

Kültür Mahallesi'nin sosyal yaşamı çevresine göre oldukça gelişmiş durumdadır. Mahallenin konumu, sosyal mekânlarının fazlalığı, mahalle sakinlerinin önemli bir kısmının üniversite öğrencilerinden oluşması gibi sebeplerle yoğun bir sosyal hayat yaşanmaktadır. Özellikle Hürriyet Caddesi üzerinde 25 kadar kafe ve restoran gece geç saatlere kadar açık durmakta ve her zaman yoğun olmaktadır. Buralara genelde mahallede ikamet eden öğrenciler ilgi göstermekle birlikte mahalle dışından da pek çok öğrenci ve vatandaş gelmektedir. En çok rağbet gören alanları, $\% 67$ oranında kafe ve $\% 72$ oranında restoranlar oluşturmaktadır (Tablo 4). Kafeler birer toplanma, sosyalleşme, eğlenme ve vakit geçirme yerleri olarak görülmektedir. Bu mekânlar o kadar yoğun ilgi görmektedir ki sürekli yenileri açılmaktadır. Her biri ortalama en az 150-200 kişilik olan 8 büyük kafenin akşam saatlerinde tamamen dolu olması yoğunluğu ifade etmekte önemlidir. Elbette yoğun ilgi gören diğer mekânlar ise restoranlardır. Öğrenciler arasında çok rağbet gören hızlı ve hazır yemek ihtiyacı buradaki restoranlardan karşılanmaktadır. Popüler kültürün getirmiş olduğu elemanlardan fastfood, pizza ve diğer hazır gıdalara ait çok sayıda restoran bulunmaktadır.

Kültür Mahallesi’nde yapılan görüşmelerde halkın sosyal mekân kullanımlarının yoğun olduğu tespit edilmiştir. Mahalle sakinlerinin \%45'i haftada en az 2-3 kez kafeleri ve restoranları kullandığ 1 belirtmiştir. Her gün kafelere gidenler \%20 oranındadır (Tablo 5). Genelde herkesin kendine göre tercih ettiği belirli mekânlar vardır ve büyük çoğunluğu buralara arkadaş çevresiyle birlikte ve en az 2 kişi olarak gitmektedir. Düşük gelirli öğrenciler kafelere daha az gittiklerini söylemişler bazen kıraathanelerde vakit geçirdiklerini belirtmişlerdir. Mahallede yaşayan ailelerde zaman zaman kafe ve restoranları kullandıklarını, pastanelerden faydalandıklarını belirtmişlerdir. Emekli kesim genellikle kıraathaneleri tercih etmektedir. Pek çok öğrenci mahalledeki mekânların oldukça yeterli olduğunu ve bu yüzden başka yerlere gitme ihtiyacı duymadıklarını söylemiş̧ir. Yerleşmek için Kültür Mahallesi'ni tercih etme sebeplerinden bir tanesinin de bu olduğunu ve sosyal yaşama ait ihtiyaçlarını rahatlıkla karşıladıklarını belirtmişlerdir.

Elde etmiş olduğumuz bulgular sosyo-kültürel farklılıklar ile mekân kullanımı arasında önemli bağlantılar olduğunu ortaya koymaktadır. Bahsettiğimiz gibi Gülveren Mahallesi’nde sosyal faaliyet imkanları oldukça zayıftır, insanların yemek yiyebileceği, vakit geçirebileceği, 
oturup dinlenebileceği mekânlar çok az sayıdadır. Şüphesiz ki bu durumun gerçekleşmesinde, mahallede bu tür faaliyet ve isteklerde bulunan sosyal kitlenin azlığı önemli bir faktördür. Kafe ve restoran gibi işyerlerinin temel müşteri kitlesini oluşturacak genç neslin azlığı mahallede bu tarz yatırımların gerçekleşmesinin önünde bir engel oluşturmaktadır. Ayrıca gelir seviyesi yüksek olmayan mahalle sakinlerinin önemli bir kısmının asıl önceliklerini, bu tarz mekânlar oluşturmamaktadır. Mahalle sakinlerinin bir kısmı genellikle bu ihtiyaçlarını civardaki mahallelere giderek karşılamaya çalışmaktadır.

Kültür Mahallesi’nde ise üniversite öğrencilerinin varlığı büyük bir potansiyel oluşturmaktadır. Bu potansiyel mahallenin değişmesine ve küçük çapta bir evrim geçirmesine yol açmıştır. Bu sayede yoğun bir sosyal hayat ve her gün yenileri açılan mekânlar ortaya çıkmıştır. $\mathrm{Bu}$ sosyokültürel yapı devam ettiği sürece bu durumun devam edeceği ve Kültür Mahallesi'nin bir "ögrenci mahallesi”" olarak anılacağı düşünülmektedir.

\section{Sonuç}

İnsanlar, çevresiyle uyum halinde yaşamak isteyen canlılardır ve çevrelerini kendi özellik ve isteklerine göre düzenlemek isterler. Bu nedenle değişik sosyo-kültürel yapıdaki topluluklar farklı ihtiyaç ve isteklere sahiptir. Günümüzde iletişim ve ulaşım imkanlarının gelişmesi ve popüler kültürün etkisiyle, insanların istek ve ilgilerinde değişmeler yaşanmıştır. Özellikle genç nesil ve üniversite öğrencileri bu değişimin en belirgin yaşandığı gruplardandır. Son dönemde fastfood, hazır yemek, kafe ve eğlence kültürü öğrenciler arasında yoğun ilgi görmektedir. Öğrenciler yaşayacakları çevreyi bile belirlerken bu tip mekânların var olduğu ve sosyalleşebilecekleri alanları tercih etmeye çalışmaktadır. Sonuçta üniversite öğrencilerinin yoğun olduğu alanlarda bu mekânlar artmaya başlamakta ve çevrede bir dönüşüm gerçekleşmektedir.

Araştırma sahasında elde ettiğimiz sonuçların ortaya koyduğu gibi mekânların şekillenmesinde sosyo-kültürel özelliklerin son derece büyük bir etkisi vardır. Bu sayede Akdeniz Üniversitesi'ne aynı mesafede bulunan Kültür ve Gülveren mahalleleri tamamen farklı iki yapı ve görünüme sahip olmuşlardır. Geçmişte benzer özelliklere sahip olan bu iki mahalle arasında üniversite öğrencilerinin Kültür Mahallesi'ne yerleşmeye başlaması ve sosyo-kültürel yapının değişmesiyle büyük bir uçurum meydana gelmiştir. Her iki mahalle sakinleriyle yapılan görüşmelerde son dönemde Kültür Mahallesi'nde büyük bir gelişim yaşandığını ve sadece iki-üç sene önce bile böyle bir değişimi tahmin edemediklerini söylemişlerdir. Önceden Gülveren Mahallesi'nin daha eski ve değerli olduğunu ve ancak son dönemde Kültür Mahallesi'nde her şeyin tersine döndüğünü belirtmişlerdir. Gülveren Mahallesi'nde bir market sahibi "iki sene önce bana Kültür Mahallesi'nde bedava bir dükkân verseler almazdım ama şimdiki gelişmeleri görünce inanamiyorum" demiştir.

Sonuçta Kültür Mahallesi'nin yaşadığı bu gelişim mahalleyi tercih eden ve etmek isteyen insanların istek ve beklentilerine cevap verilmesinden dolayı ortaya çıkmıştır. Pek çok öğrenci kalacakları yeri belirlemeden önce her iki mahalleyi de gezmekte ve daha sonra karar vermektedir. Sonunda büyük çoğunluğu Kültür Mahallesi'nin sunduğu imkanları göz önüne alarak burayı tercih etmektedir. Gülveren Mahallesi'nde de öğrenci isteklerine uygun benzer bir gelişim yaşanırsa her iki mahalle arasındaki farklılıklar zamanla azalabilir veya ortadan kalkabilir. 


\section{KAYNAKÇA}

Arslanoğlu İ. (2000). "Kültür ve Medeniyet Kavramları". Türk Kültürü ve Hacı Bektaş Veli Araşttrma Dergisi 15 (2000) 370-391.

Crang M. (1998). Cultural Geography. Routledge 1998.

Erdoğan İ. (2004). "Popüler Kültürün Ne Olduğu Üzerine”. Bilim ve Aklın Aydınlığında Eğitim Dergisi 57 (2004) 1-18.

Erkal M. (1982). Sosyoloji (Toplumbilim). Trabzon 1982.

Hacısalihoğlu Y. (2000). Küreselleşme Mekânsal Etkileri ve İstanbul. İstanbul 2000.

Hofmann S. G. (2006). ”The Importance of Culture in Cognitive and Behavioral Practice”. Cognitive and Behavioral Practice 13/4 (2006) 243-245.

Işık Ş. (2008). "Türkiye'de Üniversitelerin Kentleşme Üzerine Etkileri". Ankara Üniversitesi Türkiye Coğrafya Araştırma ve Uygulama Merkezi TÜCAUM, V. Ulusal Coğrafya Sempozyumu 2008 Bildiriler Kitabl (16-17 Ekim 2008). Ankara (2008) 123-134.

Limon B. (2012). "Kültürel Değişim Sürecinde Popüler Kültür ve Kitsch Kavramı”. İdil Sanat ve Dil Dergisi 1/3 (2012) 106-115.

Özey R. (2014). Kültürel Coğrafya. İstanbul 2014.

Şahin M. C. (2005). “Türkiye'de Gençliğin Toplumsal Kimliği ve Popüler Tüketim Kültürü”. Gazi Eğitim Fakültesi Dergisi 25/2 (2005) 157-181.

Tümertekin E. \& Özgüç N. (2010). Beşeri Coğrafya İnsan, Kültür, Mekân. İstanbul 2010. 